\title{
PUSAT KEGIATAN DAN PENDIDIKAN ANAK- ANAK PENYANDANG AUTIS DI MAKASSAR
}

\author{
Syamsu Rizal ${ }^{1}$, St. Aisyah Rahman ${ }^{2}$, Mutmainnah $^{3}$ \\ Jurusan Arsitektur Fakultas Sains \& Teknologi UIN Alauddin Makassar \\ E-mail: aisysipala@gmail.com, mutmainnah_sr@yahoo.com
}

\begin{abstract}
The Autism children are who experience barriers to the development of speech and occupational behavio. Recent research shows one in 150 children in Indonesia are now suffering from autism. Comparison of children with autism with normal children around the world reached 1:100. In South Sulawesi, no less than 1,000 children under the age of five years ( toddlers) affected with autism. In order to develop an autistic child is required pontesi container that can reflect some of the child protection legislation and government programs are compulsory nine years. Containers must be based on a system of activities and special education for children with autism. The goal is to identify children with special needs with emphasis on healing the child to be able to blend in social life. From the analysis of the need for container have been the right location and in accordance with the designation of the central building and educational activities of children with autism in Makassar, which is in Tamalanrea. This design results of the analysis combined with reference to relevant theory. Shape design philosophy begins with geometric forms and cylinder block. The shape of the building the appearance of an effect on the processing site and the structure and materials used, while also considering other factors such as utilities and supplies bangunanannya.
\end{abstract}

Keywords: Education, children, autism .

\footnotetext{
${ }^{1}$ Alumni Jurusan Teknik Arsitektur UIN Alauddin Makassar Angkatan 2006

${ }^{2}$ Dosen Jurusan Teknik Arsitektur UIN Alauddin Makassar

${ }^{3}$ Dosen Jurusan Teknik Arsitektur UIN Alauddin Makassar
} 


\section{PENDAHULUAN}

Anak berkebutuhan khusus adalah yang termasuk anak yang mengalami hambatan dalam perkembangan perilakunya. Perilaku anak-anak ini, yang antara lain terdiri dari wicara dan okupasi, tidak berkembang seperti pada anak yang normal. Pada umumnya anak berkebutuhan khusus juga disebut hanya anak autis. Berdasarkan hasil penelitian terbaru menunjukkan satu dari 150 balita di Indonesia kini menderita autis. Laporan terakhir WHO memperlihatkan hal serupa, yang mana perbandingan anak autis dengan anak normal di seluruh dunia, termasuk di kota - kota besar Indonesia telah mencapai 1 : 100. (Hr. Suara Karya 11/3/05) dan berdasarkan pengamatan Yayasan Autis Indonesia jumlah anak berkebutuhan khusus di Indonesia pada saat ini adalah 1 : 166. Sedangkan di Sulawesi selatan dalam beberapa tahun terakhir diketahui, tak kurang dari 1.000 anak di bawah usia lima tahun (balita) terserang autis (www.gatra.com, 2012/06/07). Dalam rangka pengembangan pontesi anak berkebutuhan khusus diperlukan wadah yang dapat merefleksikan sebagian dari undang-undang perlindungan anak dan program pemerintah yaitu wajib belajar sembilan tahun. Wadah tersebut harus mengacu pada sistem kegiatan dan pendidikan anak-anak khusus penderita autis. Pusat pengembangan potensi anak berkebutuhan khusus merupakan suatu sarana terapi dan pendidikan yang bertujuan mengidentifikasi anak-anak yang berkebutuhan khusus dengan mengutamakan kesembuhan anak tersebut agar dapat berbaur dalam kehidupan sosial.

\section{TINJAUAN PUSTAKA}

\section{Pengertian Pusat Kegiatan dan} Pendidikan Anak Penyandang Autis

Pusat Kegiatan dan Pendidikan Anak Penyandang Autis adalah wadah memperoleh kegiatan penanganan yang khusus serta pengajaran dan pengetahuan sekaligus sebagai sarana aktivitas pengobatan yang didirikan khusus anak penyandang autis 5-12 tahun, yang bertujuan menumbuhkan serta mengembangkan potensi kedewasaan anak yang diharapkan dapat bermanfaat bagi masa depan. (dari berbagai sumber di www.google.com).

\section{Pengertian Anak Autis}

Anak autis adalah salah satu di antara sekian banyak sindrom yang menyerang sel saraf motorik. Keterbatasan ini yang menyebabkan anak autis sangat kurang pengaruh terhadap lingkungan di sekitarnya. Ibarat sebuah benih, anak autis sering kali dipandang sebagai sesuatu yang sederhana. Padahal, perbedaan yang mereka miliki dengan layaknya anak normal lain juga didapati potensi perkembangan yang "istimewa". Tidak keseluruhan anak autis menyulitkan orangorang yang berada di sekitarnya. Banyak dari mereka yang memiliki kelebihan, baik secara akademik maupun non-akademik. Oleh karena itu, pengenalan serta pembelajaran bagi penderita autis sangat penting, berkaitan dengan perkembangan sel motorik mereka yang lemah terhadap sosialisasi lingkungan. Benih merupakan zat yang sederhana, tetapi terkandung banyak informasi yang menjadi cikal bakal bentukan sempurna. Sama halnya dengan anak autis yang seringkali tidak diperdulikan atau diabaikan, padahal mereka makhluk ciptaan Tuhan yang tidak ternilai harganya. Manusia diciptakan dengan kelebihan dan kekurangannya, semata-mata agar mereka bersyukur kepada penciptanya.

\section{Tinjauan terhadap Konsep Arsitektur} Prilaku

Arsitektur perilaku adalah Arsitektur yang dalam penerapannya

selalu menyertakan pertimbanganpertimbangan perilaku dalam perancangan. Arsitektur muncul sekitar tahun 1950. Pertimbangan-pertimbangan ini pada awalnya dibutuhkan untuk perancangan obyek-obyek arsitektur tertentu, misalnya rumah sakit jiwa, pusat rehabilitasi 
narkoba, rumah sakit anak, sekolah luar biasa (SLB) atau pusat autisme. Dalam erkembangannya,

ternyata banyak perkembanganya arsitektur yang dapat didekati dengan pendekatan perilaku di dalam perancangannya, misalnya mall, restoran, sekolah, stasiun kereta api, dan lain-lain.

Menurut Donna P. Duerk menjelaskan bahwa manusia dan perilakunya adalah bagian dari sistem yang menempati empat dan lingkungan, sehingga perilaku dan lingkungan tidak dapat dipisahkan secara empiris. Karena itu perilaku manusia selalu terjadi pada suatu tempat dan tidak dapat di evaluasi secara keseluruhan tanpa pertimbangan faktor-faktor lingkungan.

Hubungan antara lingkungan dan perilaku; Lingkungan yang mempengaruhi perilaku manusia. Lingkungan merupakan bagian terpenting yang akan membangun kepribadian, terutama kepribadian manusia. Lingkungan juga bisa dikatakan sebagai cermin untuk diri kita. Lingkungan yang baik akan membentuk pribadi yang baik, sementara lingkungan yang buruk akan membantuk sifat dan perilaku yang buruk. Perilaku manusia yang mempengaruhi lingkungan. Manusia juga mempunyai peran penting dalam merawat, melestarikan maupun menjaga lingkungan. Menurut Moore (1976) pengertian perilaku merupakan bagian dari program sosial untuk kesejahteraan masyarakat dan fokusnya adalah hubungan saling menunjang antara manusia sebagai individu atau kelompok dan lingkungan fisiknya, untuk meningkatkan kehidupan melalui kebijakan perencanaan dan perancangan perilaku sangat mempengaruhi perancangan dan aktivitas yang berlangsung di dalamnya. Pembentukan perilaku seseorang adalah suatu proses karena pengaruh budaya dan adanya faktor pengaruh lingkungan yang saling terkait satu dengan yang lain. Heidegger (1971) berkata; Arsitek harus menanggapi hal ini dan apabila memungkinkan harus meningkatkan identitas lingkungan dan sense of place.
Norberg Schulz (1979) dalam mengemukakan Genius Loci mengatakan: Arsitek harus menciptakan Place dan bukan hanya Space dengan mengemukakan sintesa dari keseluruhan komponen lingkungan, termasuk sosial. Hasil yang didapat harus menemukan komposisi yang terbaik dari lingkungan fisik dan konteks budaya, dan juga kebutuhan dan keinginan dari pengguna. Yang tidak terlepas dari ruang dan waktu. Kebanyakan desain yang berhasil meminimalkan campur tangan di

dalam merubah sosial dan fisik dibandingkan dengan desain dengan perubahan yang radikal. Ini disebut juga pendekatan ekologikal (Mestika,

2010 dalam Marcella, 2012). Kesimpulan yang dapat kita ambil adalah pentingnya menciptakan Place dan bukan hanya Space dengan mengemukakan sintesa dari keseluruhan komponen lingkungan, termasuk sosial. Pengalaman dari suatu tempat yang unik adalah suatu pengalaman yang tidak terlupakan. Sehingga keunikan dari suatu tempat harus ditingkatkan. kita hanya perlu untuk menyusun yang telah ada daripada menciptakan sesuatu yang baru. Sesuatu yang sesuai dengan ruang, waktu, tempat, kegiatan, dan pengguna.

\section{Bentuk dan Penampilan Bangunan}

Bangunan pusat kegiatan dan pendidikan anak-anak penderita autis adalah bangunan atau lembaga pendidikan yang diperuntukkan bagi anak-anak yang memiliki kelainan perkembangan neurologisnya yang mengakibatkan penderita mengalami keterlambatan dalam perkembangan bahasa, komunikasi, dan interaksi. Oleh sebab itu, rancangan eksterior dan interior bangunan mengikuti karakteristik anak autis. Konsep bangunan menampilakan bangunan yang cukup unik dan modern.Konsep modern bertujuan sebagai simbolisasi akan harapan masyarakatakan kesembuhan anak-anak autis di masa mendatang. Konsep yang unik bertujuan agar bangunan ini menampilkan kesan rekreatif agar dapat menarik perhatian anak-anak autis untuk 
menjadikan sekolah ini sebagai tempatnya beraktivitas sehari-hari. Analisis terhadap bentukan bangunan tidak hanya mengutamakansegi estetis, tetapi harus mempertimbangkan keamananan terutama persepsianak autis terhadap bentukan yang dirancang. Bentukan-bentukan yang harus dihindari adalah sebagai berikut; Bentukan yang monumental, bentukan atau desain yang terlalu rumit, bentukan yang bersudut, dapat membahayakan aktifitas anak autis

Analisis bentukan dapat dilakukan sebagai berikut; menggunakan bentukan sederhana dan tidak terlalu mencolok (warna). Kekurangan; Terkesan monoton, sehingga anak autis mudah bosan. Menggunakan bentukan alami dari lingkungan (batu, air, atau material alam lainnya).

Kelebihan; Anak autis lebih mudah mengenal bentukan alami, sehingga mempermudah proses penyembuhan. Kekurangan; Cukup sulit memperoleh bentukan alami yang sesuai terkait dengan modul pembelajaran. Lingkungan Alamiah Lingkungan alamiah adalah elemenelemen alami dan tempat sekitar tapak (iklim, air, tanah, topografi, vegetasi, dan kemakhluk hidup lainnya) yang penting bagi rancangan tapak.

\section{Studi Banding}

Studi banding objek Pusat Pendidikan dan Terapi Anak Autis Buah Hatiku

Tempat ini merupakan pendidikan khusus bagi keluarga yang memiliki anak penderita autis dan gangguan perkembangan lainnya. Berlokasi di kota Makassar, tepatnya Jl. G.

Latimojong No.129 C Makassar. Pusat informasi dan terapi ini menggunakan tema perilaku (behavior) sebagai tema pokok perancanganbangunan.

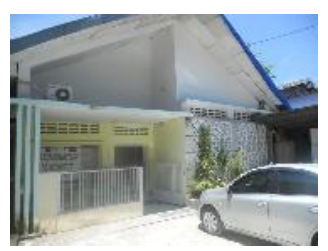

Gambar 2.8. Tampak Depan Buah

HatiSumber : dokumen pribadi, 2012
Jenis-jenis rung yang tersedia antara lain sebagai berikut; ruang tunggu, ruang konsultasi, ruang terapi sensori integral, ruang terapi one on one,

\section{Studi Banding Tema Perilaku}

\section{Ron Leaf, Seal Beach California}

Ron leaf, merupakan sebuah pusat terapi dan informasi untuk anak-anak berkebutuhan khusus, yang berlokasi di Seal Beach California. Metoda yang digunakan dalam menerapi anak-anak adalah ABA (Applied Behaviour Analisys). Jenis ruang yang tersedia antara lain sebagai berikut:

R. Terapi One on one, merupakan metoda pengajaran satu terapi dan 1 anak. Pada area ini lantai menggunakan karpet, bahan ini baik digunakan untuk menjaga kestabilan suhu dan meredam suara. Kelas ini merupakan kelas besar, yang terdapat beberapa area yang tidak menggunakan sekat untuk fungsi dinding namun menggunakan perabot. Pencahayaan yang menggunakan sistem artificial light, dengan syarat lampu yang tidak menyilaukan.

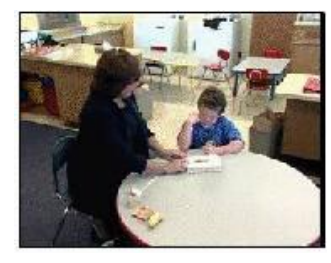

Gambar 2.11. Ruang terapi one on one Sumber: www.infantilautis.co.id

Classical Class. Pada area ini, merupakan kegiatan terapi bersama dengan murid lain. Area ini membutuhkan space yang lebih besar. Suasana yang diciptakan lebih variatif. Terlihat pada penggunaan wallpaper bergambar pada dinding, bentuk dan warna perabot yang menyesuaikan tema. Lantainya menggunakan karpet yang merupakan salah satu bahan alternatif yang digunakan untuk ruang kelas anak berkebutuhan khusus. 
Nature

National Academic Journal of Architecture

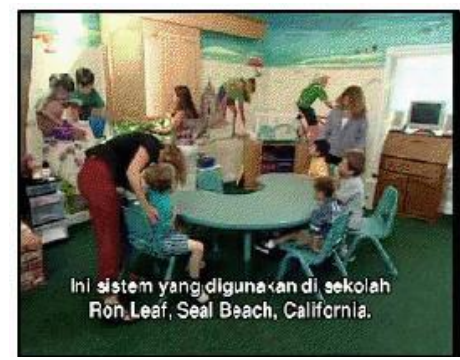

Gambar 2.12. Classical class

Sumber: www.infantilautis.co.id

Sensori Integration. Pada area ini merupakan area yang melatih sensor motorik anak dengan berkebutuhan khusus agar dapat mengkoordinasi fisik dengan baik. Area ini membutuhkan space yang luas agar dapat menampung peralatan main seperti ayunan, kolam bola, dan lain sebagianya. Lantai yang digunakan berbahan empuk seperti, matras dan karpet agar aman bagi anak. Pencahayaan yang digunakan pencahayaan alami dan buatan.
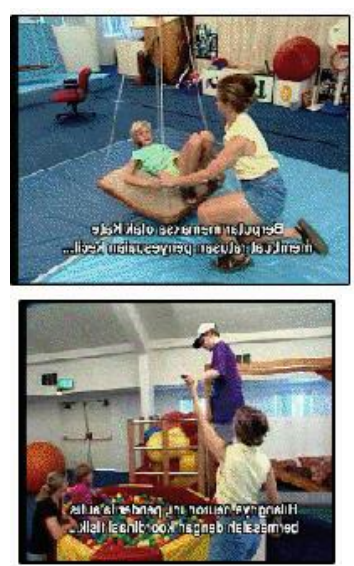

Gambar 2.13. Sensori IntegrationSumber: www.infantilautis.co.id

\section{Music Clas}

Kelas musik merupakan kelas yang difungsikan agar anak-anak mengenal dan menirukan bunyi. Pada area ini, suasana yang diciptakan hangat dan menyenangkan, terihat dari penggunaan bahan dan warna yang natural seperti kayu plantai dan dinding. Pencahayaan menggunakan daylight. Perabot yang digunakan tidak seperti lazimnya, fasilitas duduk menggunakan bola, difungsikan agar anak-anak tersebut lebih dapat menjaga keseimbangan dan lebih nyaman. Area koridor ini di jadikan ruang tunggu dengan lebar $2 \mathrm{~m}$

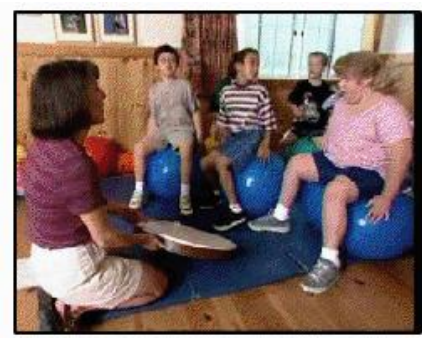

Gambar 2.14. Music class

Sumber: www.infantilautis.co.id

Beberapa desain baik yang dapat dijadikan literature perancangan antara lain sebagai berikut; pembagian jumlah ruang dan dimensinya sesuai dengan kapasitas pengguna, sifat ruang, jenis aktivitas, serta suasana yang diciptakan, sistem kenyamanan thermal (pencahayaan, penghawaan, akustik) sudah terpenuhi dengan baik.

\section{Surabaya International School (SIS)}

Sebagai perbandingan ketiga, adalah sekolah umum yang memiliki sistem pemprograman ruang yang baik. Studi pembanding adalah Surabaya International School (SIS). pendidikan dan pengajaran yang baik dan memadai untuk kebutuhan anak-anak serta pengguna yang lainnya. Berikut ini beberapa fasilitas yang dapat dijadikan perbandingan;

\section{Library}

Pada perpustakaan ini beroperasi dari jam Pk.07.30-16.00. Penggunanya adalah murid-murid, guru, staff dan orang tua. Fasilitas yang disediakan adalah bukubuku pengetahuan dan umum, fasilitas audio visual, area khusus untuk keperluan tertentu dari guru dan murid serta area baca yang nyaman bagi pengguna.
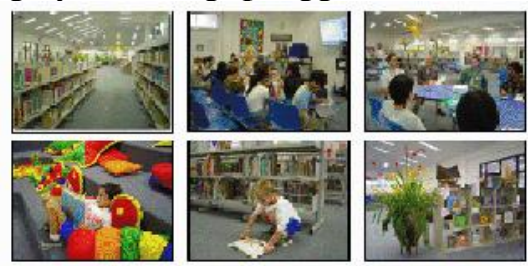
Nature

National Academic Journal of Architecture

Class

Pada tiap ruang kels di SIS, dalam 1 kelas terdiri dari 3 area yaitu area bermain, area belajar dan area untuk art activity. Sehingga

dalam menajalnkan urutan kegiatan tidak perlu untuk pindah kelas. Namun jika menggunakan kelas khusus seperti practice gym atau computer class dilakukan pada kelas yang berbeda.
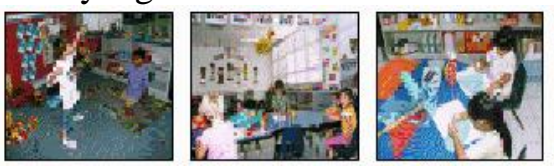

Gambar 2.16 Ruang kelas

Sumber: www.infantilautis.co.id

\section{METODE PERANANGAN}

Metode yang digunakan dengan menggunakan metode survey dan study literature dengan pengaplikasikan langsung dalam konsep desain perancangan. Teknik pengambilan data dilakukan dengan survey lapangan melihat fakta yang ada dilapangan dan dianalisis dalam bentuk konsep desain untuk menghasilkan desain perancangan yang sesuai. Selain itu teknik pengambilan data juga dilakukan dengan wawacara langsung dan selanjutnya diolah dan dikembangnkan dalam bentuk desain perancangan yang disesuaikan dengan kebutuhannya. Study literature juga digunakan disini untuk memberikan masukan berupa teori-teori pendekatan desain sekolah yang khusus anak autis dengan konsep arsitektur perilaku. Teori arsitektur perilaku menjadi tolak dasar dalam pembentukan sekolah ini dengan memahami perilaku dan karakter manusia dari suatu ruang fisik.

\section{HASIL PEMBAHASAN \\ PENDEKATAN DESAIN}

\section{Lokasi}

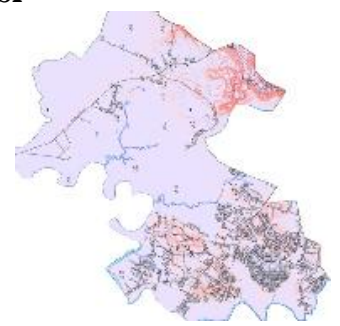

Gambar 3.1. Peta Lokasi Site
Lokasi Site dipilih terletak di Kecamatan Tamalanrea. Luas site $\pm 2,0 \mathrm{Ha}$. Batas site meliputi :

Sebelah Utara : Jl. Perintis kemerdekaan dan pertokoan

Sebelah Barat : Perumahan Bumi

Tamalanrea Permai

Sebelah Selatan : Perumahan Bumi

Tamalanrea Permai

Sebelah Timur : Gedung perpustaakaan

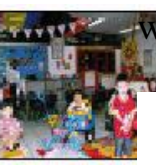

ilayah Sulawesi Selatan

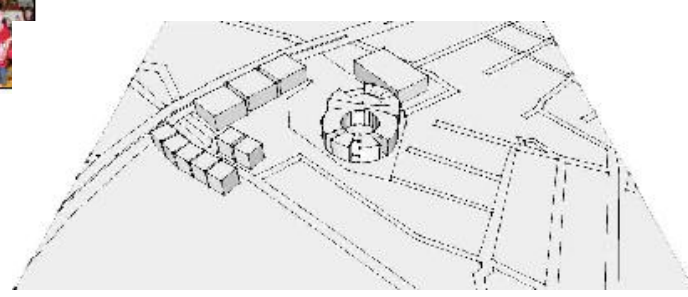

Gambar 3.2. Peta Site/Tapak

Analisis Pengolahan Site

Pengolahan Site dimaksudkan untuk memaksimalkan fungsi site, dengan menganalisis segenap potensi dan permasalahan yang terdapat dalam site. Pengolahan site didasarkan pada pertimbangan-pertimbangan berikut ini
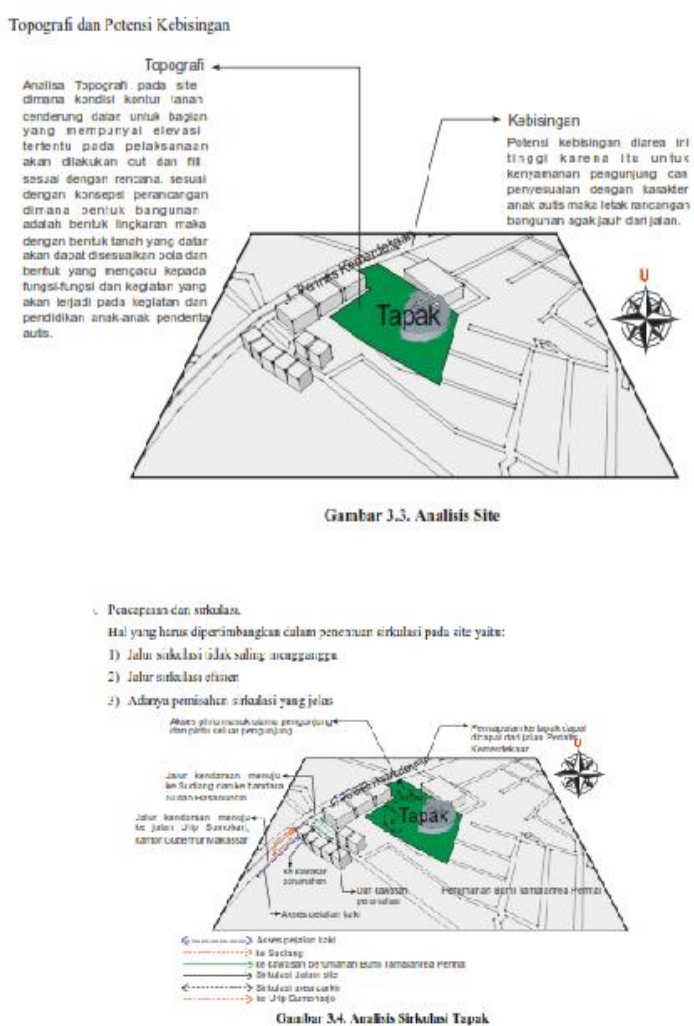


\section{Orientasi view.}

View dari dalam site melingkupi pandangan kearah Perumahan Bumi Tamalanrea Permai (arah Barat), Perumahan Bumi Tamalanrea Permai (arah Selatan), gedung perpustakaan wilayah (arah Timur) dan Jl. Perintis Kemerdekaan (arah Utara).

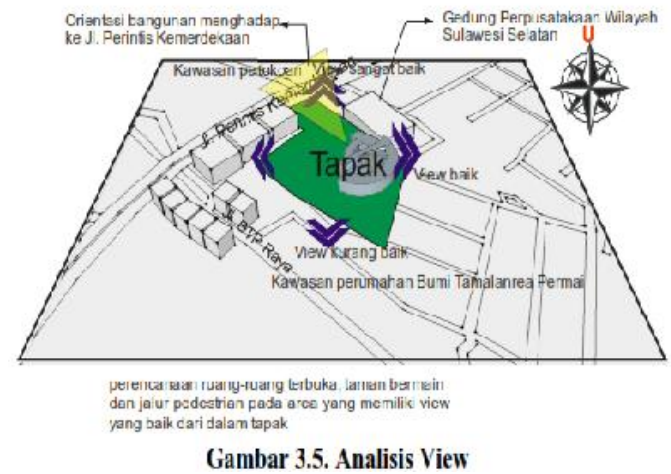

Orientasi angin dan matahari.

Perancangan bangunan harus diletakkan sedemikian rupa hingga memungkinkan pengaliran udara dalam ruang. Sinar matahari selain memberi pencahayaan alami yang berguna untuk penerangan dalam bangunan, dan bisa menimbulkan panas akibat pengaruh radiasi yang ditimbulkannya. Oleh sebab itu diperlukan solusi untuk masalah tersebut antara lain dengan penggunaan overstek, lisplank yang lebar, sunscreen dan sebagainya. Orientasi bangunan yang terbaik, ditinjau dari arah sinar matahari yaitu dengan meletakkan bangunan sejajar dengan arah matahari (Timur-Barat).

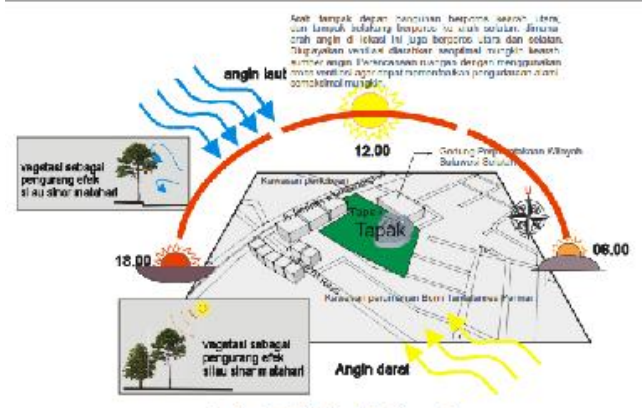

Jaringan utilitas yang tersedia area site. Jaringan utilitas diambil dari jaringan yang tersedia di sekitar site. Adapun jaringan utilitas yang tersedia yaitu, jaringan listrik dari PLN, air bersih dari PDAM, jaringan telepon dan riol kota. Selain itu, pembuatan jaringan lain seperti sumur bor sebagai sumber air bersih alternatif, dan penggunangan generator sebagai pensuplai tenaga listrik cadangan. Selain itu pemanfaatan kembali air buangan dengan cara mendaur ulang, yang bisa dimanfaatkan untuk menyiram tanaman.

\section{Pendekatan Mikro}

Program direncanakan dan di atur berdasarkan kebutuhan dan aktivitas yang diperoleh dari hasil studi yang telah dilakukan baik dengan cara studi literature maupun studi banding. Aktivitas tersebut antara lain; Proses belajar mengajar, seminar, pelatihan talenta anak berdasarkan bakat dan minat, terapi, pusat informasi para ahli.
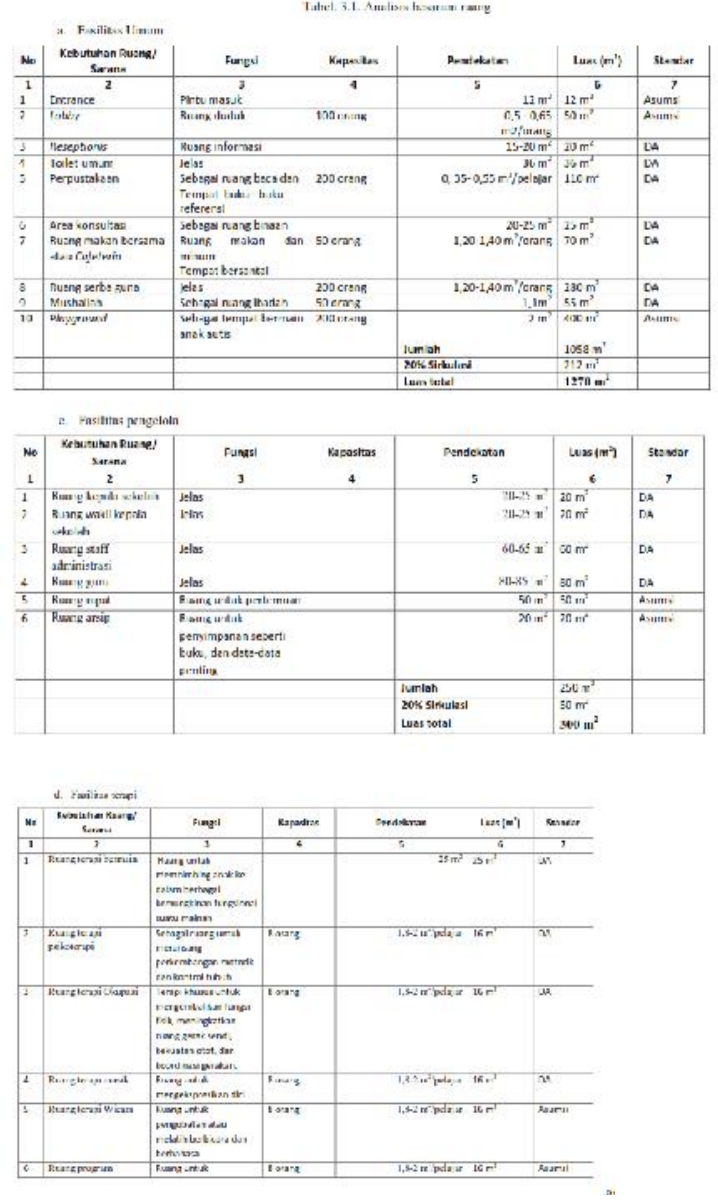
Nature

National Academic Journal of Architecture

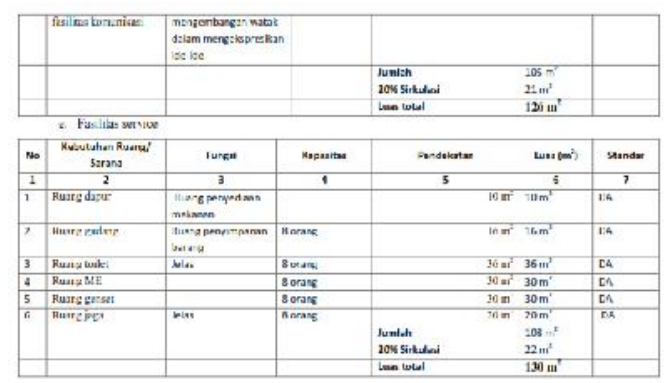

\section{Analisis Pengolahan Site}

Pencapaian dan sirkulasi dimaksudkan untuk mendapatkan penzoningan dalam site dan penentuan entrance dan pencapaian ke dalam site, dengan mempertimbangkan sirkulasi yang telah ada, serta akses dan kemudahan dalam pencapaiannya. Dari analisis pencapaian ini kita dapat tentukan area main enterance dan enterance site.

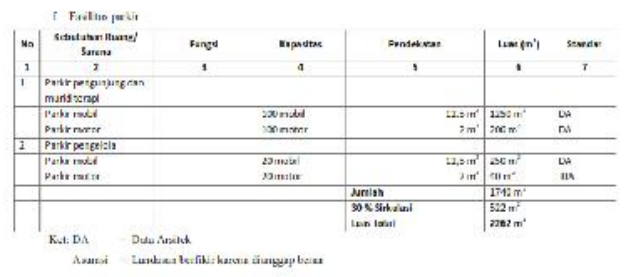

Rekapitulasi Luas Bangunan

Total 3.2. Rekapitulasi

\begin{tabular}{|c|c|c|}
\hline No. & Fasilitas & Luas \\
\hline 1 & Fasilitas Umum & $1270 \mathrm{~m}^{2}$ \\
\hline 2 & Fasilitas edukasi untuk anak autis & $415 \mathrm{~m}^{2}$ \\
\hline 3 & Pengelola & $300 \mathrm{~m}^{\prime}$ \\
\hline 4 & Tasilitas Terapi & $126 \mathrm{~m}^{2}$ \\
\hline 5 & Service & $130 \mathrm{~m}^{2}$ \\
\hline 6 & Parkir & $2262 \mathrm{~m}^{2}$ \\
\hline \multicolumn{2}{|c|}{ Total keseluruhan } & $4503 \mathrm{~m}^{2}$ \\
\hline
\end{tabular}

\section{APLIKASI DESAIN}

\section{Lokasi pilihan}

Lokasi yang dipilih adalah di Kecamatan Tamalanrea yang dalam pembagian pola ruang kota Makassar, lokasi tersebut berada pada kawasan riset dan perguruan tinggi terpadu. tml, di akses tanggal 12-042013).

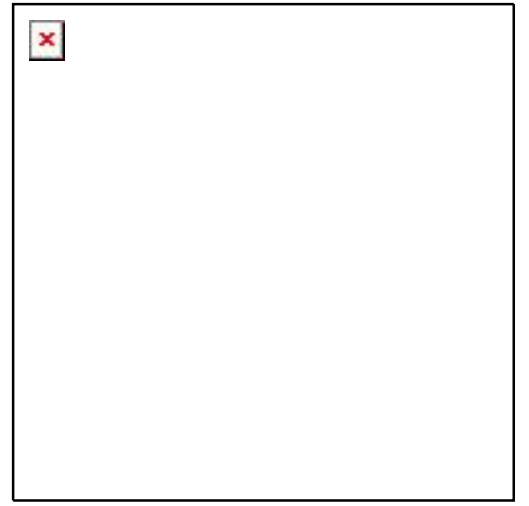

Gambar 4.1. Lokasi dan Tapak Sumber : Analisis 2013

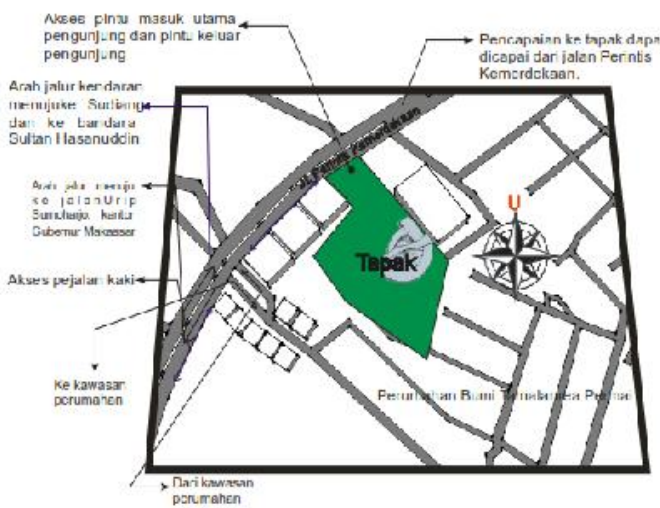

Gambar.Pecapaian dan sirkulasi

Sumber : Hasil desain ,2013

Orientasi angin dan matahari.

Dari hasil analisis orientasi angin dan matahari ini kita dapat menentukan cara pemamfaatan potensi positif dari angin dan matahari, seperti penghawaan alami, pencahayaan alami.Serta mengantisipasi segala potensi negatif dari angin dan matahari, seperti pemanfaatan sun sreen untuk mengurangi efek silau dari matahari dan pemanfaatan vegetasi sebagai pengendali angin dan mengurangi efek silau, panas dari matahari.

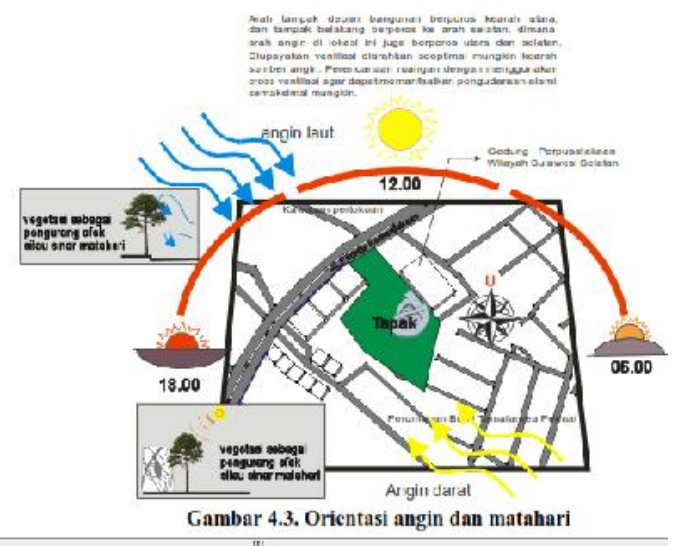

Orientasi view. 
Nature

Perumahan Bumi Tamalanrea Permai Gedung Perpusatakaan Wilayah Sulawesi Selatan View dari dalam site melingkupi pandangan kearah Perumahan Bumi Tamalanrea Permai (arah Barat), Perumahan Bumi Tamalanrea Permai (arah Selatan), gedung perpustakaan wilayah (arah Timur) dan Jl. Perintis Kemerdekaan (arah Utara).

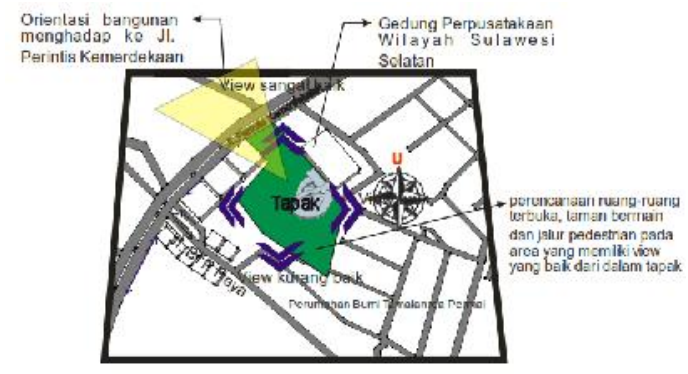

Tingkat polusi dan kebisingan.

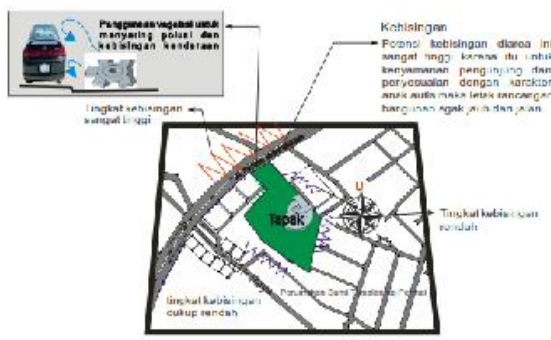

Topografi

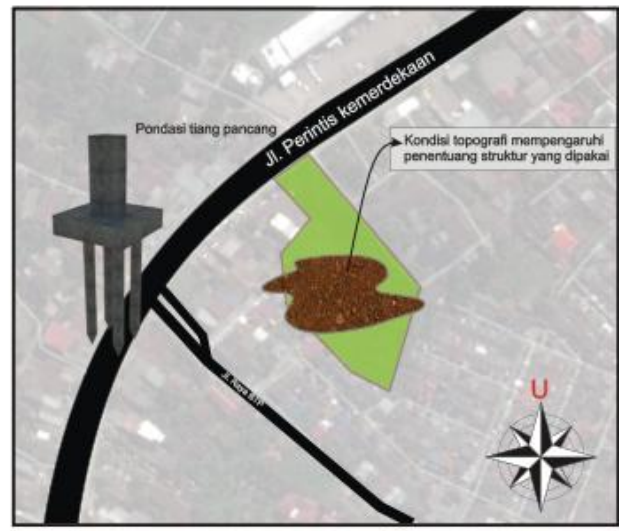

Gambar 4.6. Kondisi topografi

\section{Jaringan utilitas}
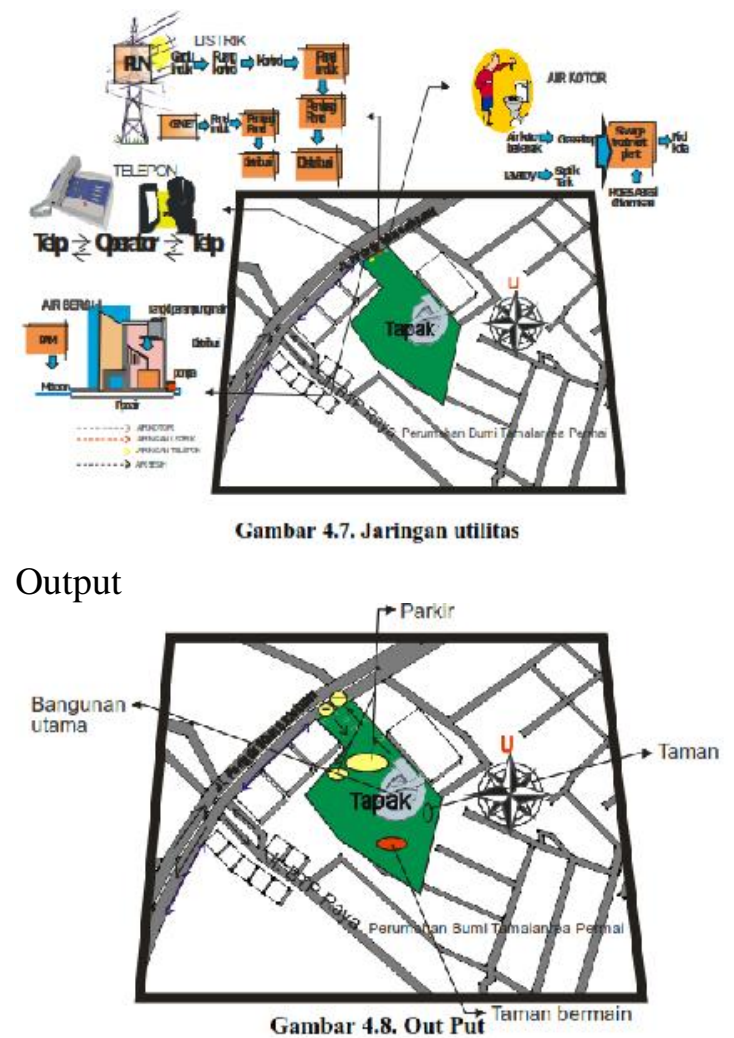

Analisis Bentuk

Beberapa macam-macam terapi autis, serta kegiatan dan fasilitas yang dibutuhkan untuk anak autis dapat menganalisis bentuk dan hubungan ruang, yaitu sebagai berikut :

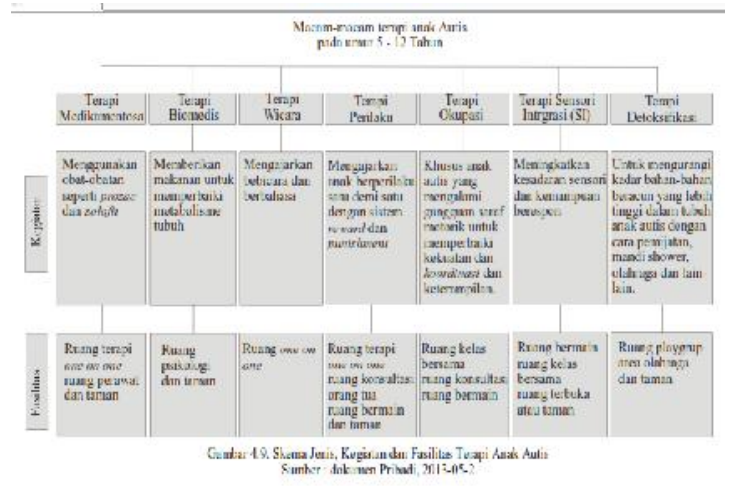

Filosofi bentuk rancang ini terbentuk dari bentuk-bentuk geometri balok dan silinder yang dapat menghubungkan ruang terapi anak autis. Bentuk-bentuk geometri adalah bentuk yang dikenal anak karena bentuktersebut sering terlihat pada mainanmainan yang mereka pakai. 


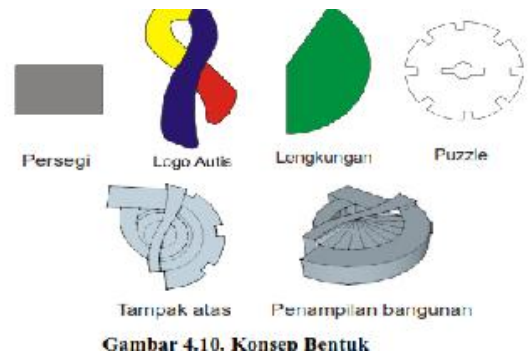

Perancangantan Mikro

Sistem penzoningan

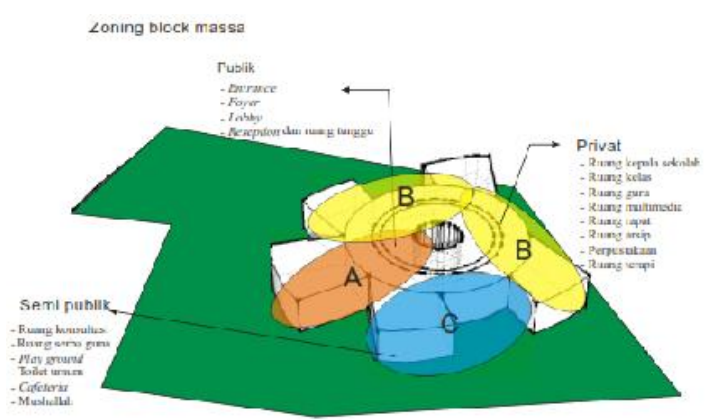

Gambar 4.11. Zoning Block Massa

\section{Acuan Perancangan Fisik dan Perlengkapan Bangunan}

Penampilan bangunan Rancangan eksterior dan interior bangunan mengikuti karakteristik anak autis. Konsep bangunan menampilakan bangunan yang cukup unik dan modern. Konsep modern bertujuan sebagai simbolisasi akan harapan masyarakat akan kesembuhan anak-anak autis di masa mendatang. Konsep yang unik bertujuan agar bangunan ini menampilkan kesan rekreatif agar dapat menarik perhatian anak-anak autis untuk menjadikan sekolah ini sebagai tempatnya beraktivitas sehari-hari.

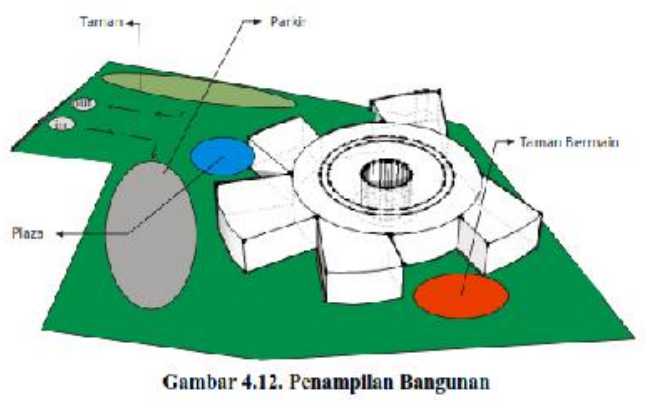

Penataan Ruang Luar.

Elemen-elemen pembentuk ruang luar yang dipakai dalam merancang bangunan pusat kegiatan dan pendidikan anak-anak penderita autis, Hard material; Paving blok dan rabat beton dekoratif sebagai jalan pada, pedestrian; Aspal sebagai bahan jalan area sirkulasi luar. Batu alam sebagai penutup dinding dan kolom luar. Lampu taman, lampu mercury, dan lampu sorot yang bervariasi sebagai penerangan ruang luar dan penghias apartemen di malam hari. Sculpture sebagai focal point Plaza sebagai area interaksi antar individu.

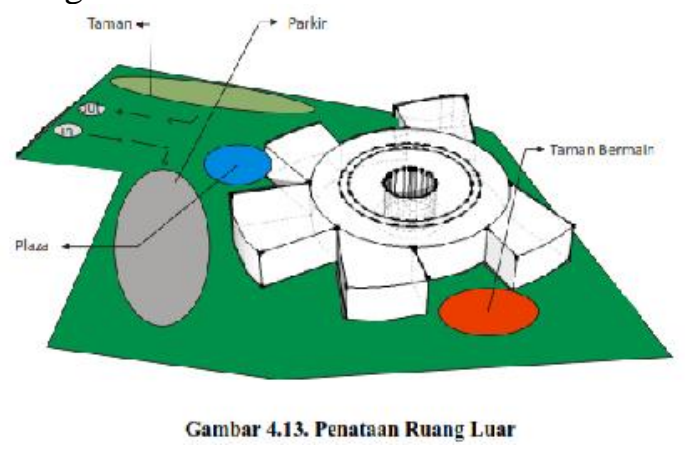

\section{Soft material.}

Jenis pohon; palm raja yang berfungsi sebagai peneduh dan pengarah. Pohon Soga, yang berfungi sebagai tanaman tepi (frame site) dan pelindung tanaman. Cemara yang berfungsi sebagai penghias tanaman dan barier noising. Sikas, Tombak raja dan palm botol sebagai penghias dan focus. Jenis perdu; semak mutiara, berfungsi sebagai tanaman hias dan batas pandang pada area parkir. Duratan atau teh-tehan sebagai penutup, batas dan pengarah. Rumput jepang berfungsi sebagai penutup tanah pada open space. Jenis tanaman berbunga untuk memperindah dan fokus taman. Penataan Ruang Dalam, Ruang yang tidak boleh terlalu mencolok dan menarik perhatian anak secara berlebihan yang dapat membuat anak tidak fokus dan tidak mau

mendengar perkataan orang lain. Penataan ruang dalam bangunan juga

memperhatikan penghawaan, pencahayaan, dan furniture yang dipilih sesuai karakter anak autis. 


\section{Struktur}

Sub struktur; struktur pondasi yang terpilih adalah pondasi rakit dan tiang pancang dengan pertimbangan mudah dalam pelaksanaan, daya dukung terhadap beban maksimal serta cocok digunakan pada lahan yang relatif datar. Dan pondasi tiang pancang cocok digunakan pada area tanah keras yang relatif dalam. Super struktur yang digunakan adalah kombinasi antara rangka dan shear wall.

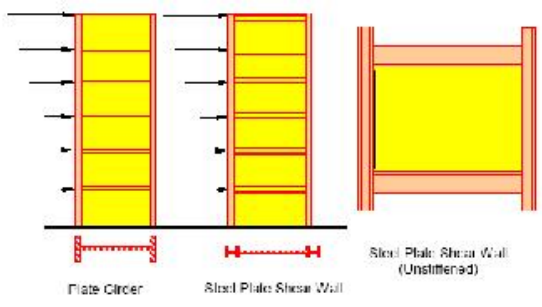

Gambar 4.17. Sistem Kombinasi Rangka dan Shear Wall

Upper struktur Struktur atap yang yang terpilih adalah baja ringan dengan penutupatap aluminium spandek.

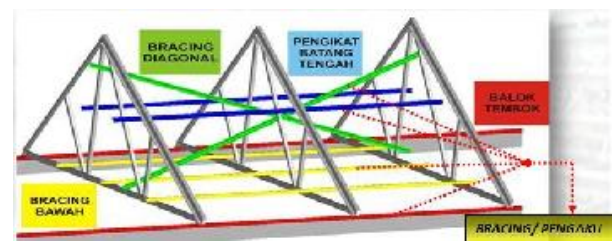

Gambar 4.18. Sistem Atap Baja Ringan

Sistem Utilitas dan Kelengkapan Bangunan; System Penghawaan alami Sistem penghawaan ruang dalam menggunakan penghawaa diperlukan alat penghisap dpoorifier) yang dapat menetralisir udara dalam ruang.

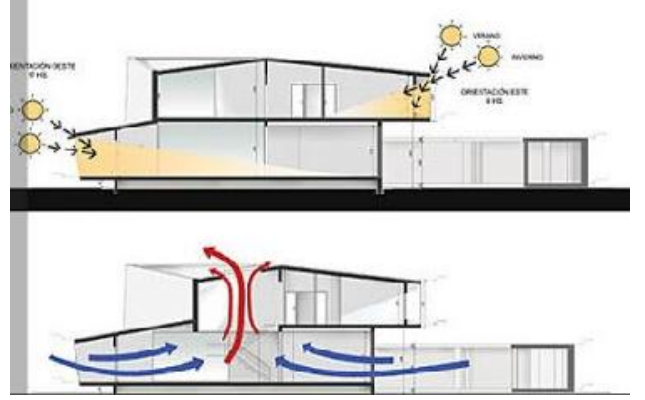

Gambar 4.19. Aplikasi Penghawaan Alami

\section{Penghawaan buatan}

Merupakan sistem pengkondisian udara untuk mencapai tingkat kelembaban udara yang diinginkan untuk kenyamanan ruang secara optimal misalnya ruang yang digunakan secara kontinyu dan ruang yang digunakan secara berkala. Sistem penerangan. Dalam perencanaan pusat kegiatan dan pendidikan anak-anak penderita autis terdapat 2 (dua) sistem penerangan, yaitu ; sistem penerangan alami

Bangunan sekolah diupayakan untuk mendapatkan sinar matahari tinggi dengan untuk mengatasi pengaruh negatifnya.

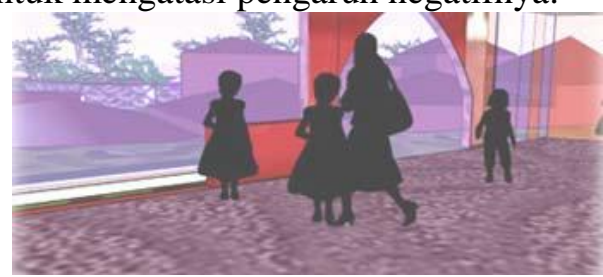

Gambar 4.21. Aplikasi Penerangan Alami

Sistem penerangan buatan. Pada bangunan pusat kegiatan dan pendidikan anak-anak penderita autis, penerangan buatan diutamakan pada ruang-ruang yang Penerangan buatan yang digunakan salah satunya dalam ruang terapi one on one yaitu dengan penerangan pada lampu kurang mendapatkan penerangan alami dan semua ruang pada malam hari, baik ruang tertutup maupun ruang terbuka. System Pencegahan Kebakaran Pencegahan bahaya kebakaran pada bangunan diperlukan peralatan yang tepat, modern, dan cepat bereaksi. Pencegahan dan penanggulangan kebakaran pangunan terbagi dua, yaitu: Pencegahan pasif, Koridor ruang lebar, minimal 1,8 meter, penggunaan pintu kebakaran dengan lebar $90 \mathrm{~cm}$ dengan indeks tahan api selama 2-3 jam, penggunaan tangga darurat dengan lebar tangga dan bordes 1,2 meter, Penerangan darurat, Pencegahan aktif System deteksi kebakaran terdiri dari smoke detector, thermo detector, flame detector. 
Perancangan, Fire alarm, Alat pemadam kebakaran ringan berupa tabung-tabung yang berisi busa dan bahan kimia

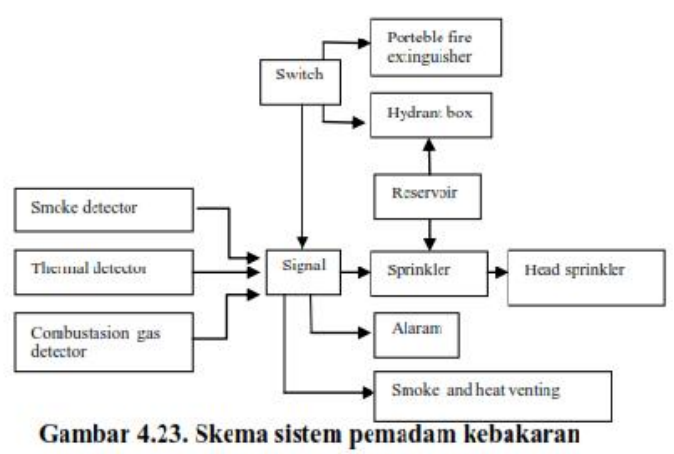

\section{Sistem penangkal petir}

Sistem penangkal petir yang digunakan adalah sistem faraday, di mana petir yang mengenai bangunan disalurkan melalui kabel tembaga ke dalam tanah untuk menetralisir sehingga tidak membahayakan baik pada bangunan maupun lingkungan sekitar.

Sistem listrik. Pada bangunan pusat kegiatan dan pendidikan anak-anak penderita autis menggunakan listrik PLN sebagai tenaga utama dan menyediakan mesin genset sebesar 100\% dari daya terpasang yang dapat bekerja secara otomatis bila listrik dari PLN padam.

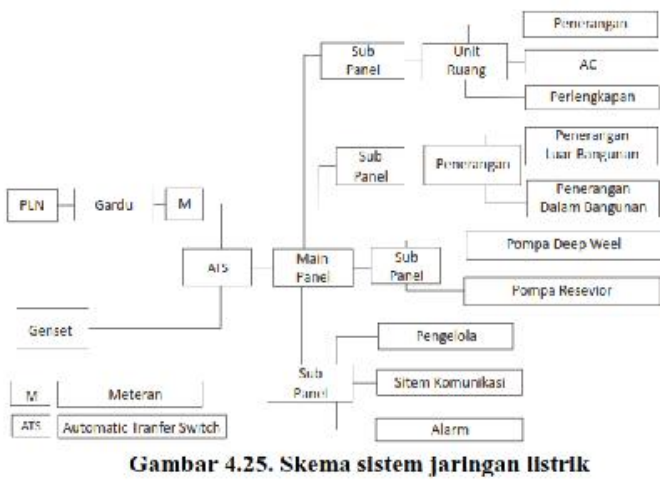

\section{System Transportasi dalam Bangunan}

System transportasi vertical, elevator atau lift, merupakan alat transportasi vertikal antar lantai dalam bangunan bertingkat secara menerus, yang hanya membutuhkan ruangan yang relatif kecil secara horizontal dan dapat mempengaruhi kualitas pelayanan gedung. Sistem transportasi manual (tangga dan ramp). Transportasi horizontal pada bangunan pusat kegiatan dan pendidikan anak-anak penderita autis ini sebagian besar menggunakan sarana transportasi manual berupa koridor/selasar. Sistem Distribusi Air Bersih; Air yang bersumber dari PAM dan sumur dalam (deep well) ditampung dalam bak penampungan; untuk pendistribusiannya air pada ground reservoir di pompa ke atas (top reservoir) selanjutnya dialirkan ke tiap-tiap lantai sesuai dengan kebutuhan dengan menggunakan gaya gravitasi bumi. Pendistribusian terbagi dua yaitu tangki untuk suplay air bersih dan digunakan untuk fire hydrant kalau terjadi kebakaran.

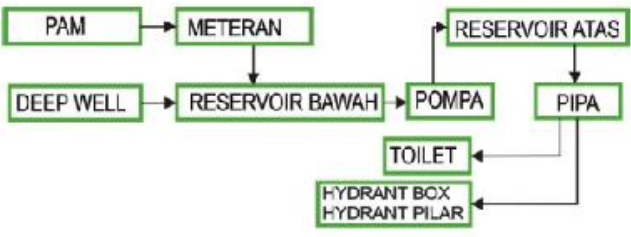

Gambar 4.28. Skema Sistem Air Bersih

Sistem distribusi air kotor Langkah pengolahan air kotor pada bangunan yaitu: Penghematan penggunaan air bersih untuk mengairi taman-taman. Pemanfaatan kembali untuk mengairi taman terutama pada musim Kemarau.

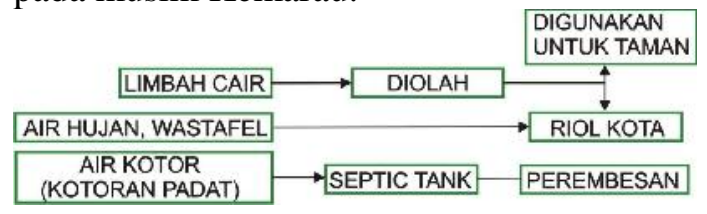

\section{Gambar 4.29. Skema Sistem Air Kotor}

Sistem pembuangan sampah sistem pembuangan sampah pada bangunan dapat dilakukan dengan dua cara, yaitu: Secara horizontal, Secara vertical. 


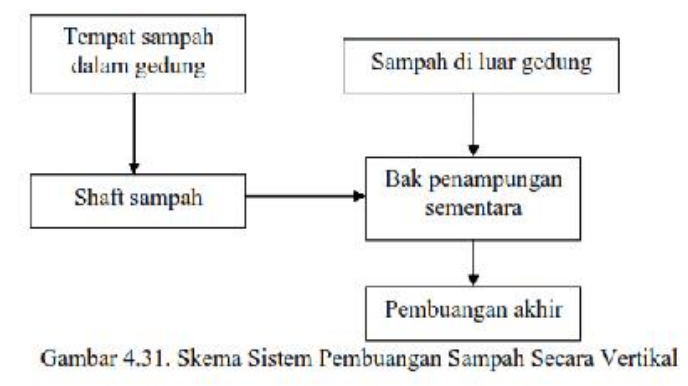

\section{APLIKASI DESAIN}

Lokasi Tapak dan Pengolahan Site

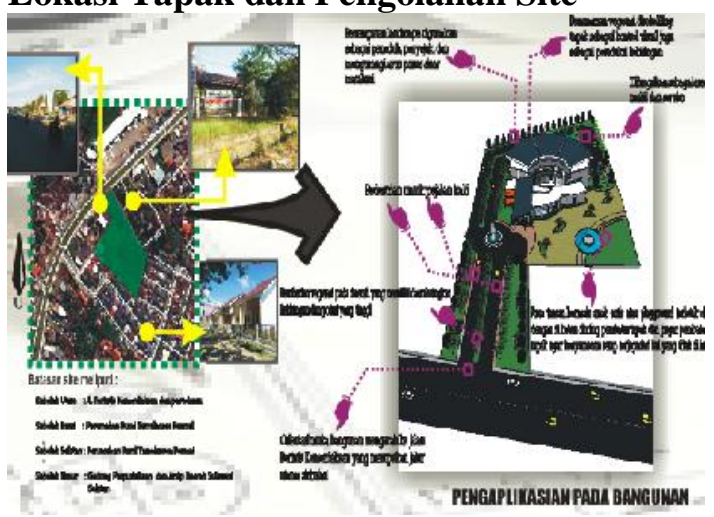

Gambar IVb.1. Desain Pengolahan Site

Sumber : Hasil perancangan, 2013

\section{Denah dan site plan}
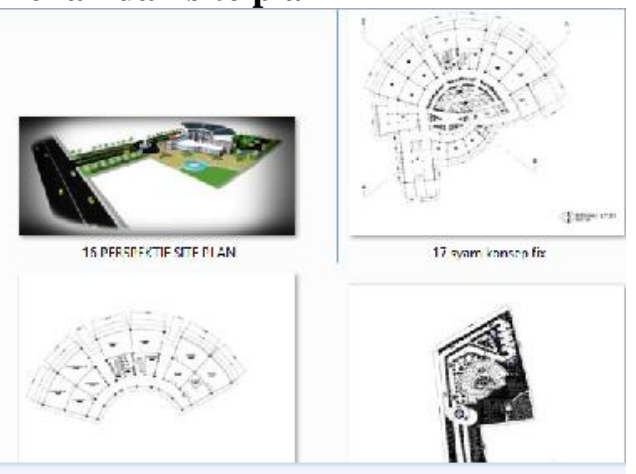

Gambar IVb.2. Desain Denah dan siteplan. Sumber: Hasil perancangan, 2013

\section{Penampilan Bangunan}

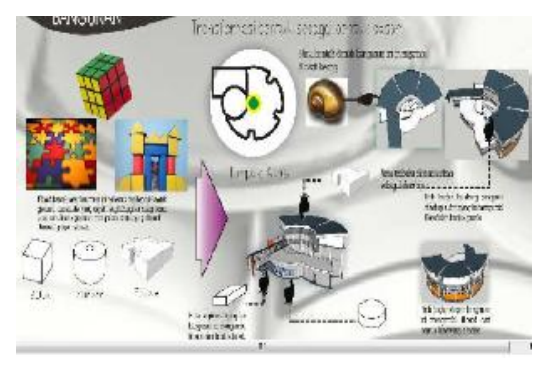

Gambar IV. Desain bentuk dan Tampilan Bangunan. Sumber: Hasil, 2013

Desain Tampak pada Bangunan

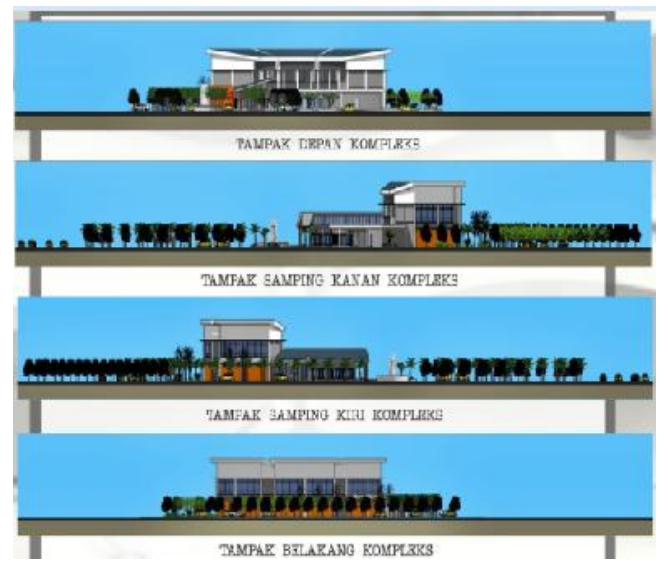

Gambar IV. Tampak Bangunan. Sumber: Hasil perancangan, 2013

\section{Sirkulasi dan jalur Pejalan kaki}

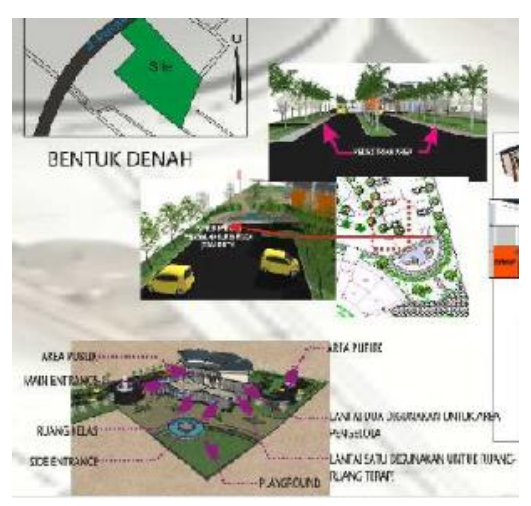

Gambar IV. Desain Sirkulasi dan jalur pejalan kaki. Sumber: Hasil,2013

\section{Desain Struktur dan material \\ Desain Struktur dan material}



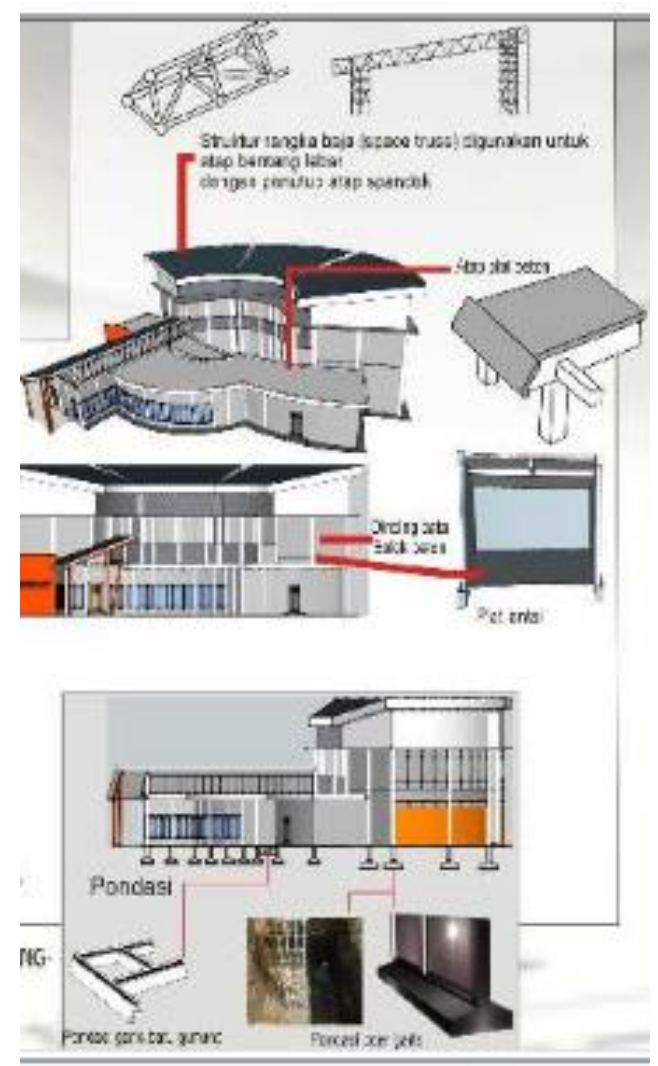

Gambar IV. Desain Struktur dan material. Sumber: Hasil perancangan, 2013

\section{Perspektif}

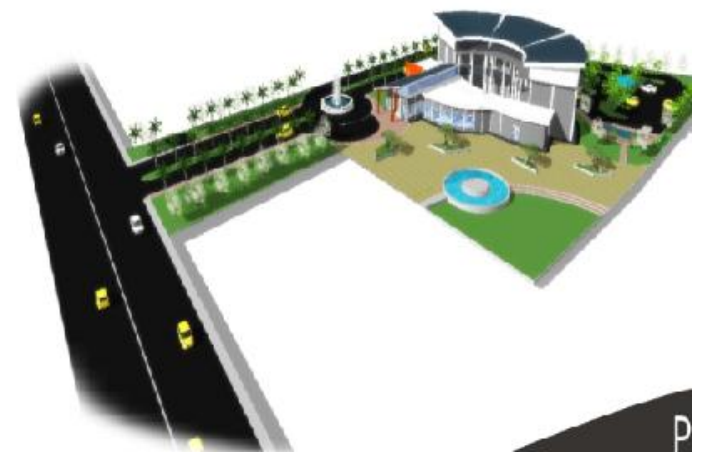

Gambar.IVb. Perspektif

Sumber : Hasil perancangan, 2013

\section{Kesimpulan}

Kesimpulannya adalah perilaku sangat mempengaruhi perancangan dan aktivitas yang berlangsung di dalamnya.
Pembentukan perilaku seseorang adalah suatu proses karena pengaruh budaya dan adanya faktor pengaruh lingkungan yang saling terkait satu dengan yang lain.

\section{DAFTAR PUSTAKA}

MangunsongF, 2009. Universitas Indonesia.

"Psikologi \& Pendidikan Anak Berkebutuhan Khusus (Jilid 1)", Jakarta.

Ulumi Devi Mamluatul, 2010, UIN Maulana Malik Ibrahim. "Pusat Pendidikan dan Terapi Autis Batu Malang", Malang.

Munandar, Utami. Prof. Dr, 2010. "Perkembangan Kreativitas Anak Berbakat", Rineka Cipta, DEPDIKNAS.

Budhiman, Melly. Dr. 2012. "Penyebab Autis Anak Usia Dini", ketua YayasanAutisme Indonesia.

Rochman Nur Fauwzia, 2006, "Pusat Terapi Khusus Autis", Surabaya

Hakim, Rustam dan Utomo Hardi (2003), "Arsitektur Lingkungan", Bumi Aksara, Jakarta.

UU RI No. 20, Tentang Sistem Pendidikan Nasional, Pustaka Widyatama.

Ernst dan Neuvert P, (1993), "Data Arsitek Jilid I,II", Erlangga , Jakarta.

Garling, T. and R. Golledge. 1993. Behavior and Environment: Psychological and

Ching, Francis, D.K., 1985, Arsitektur, Bentuk Ruang dan Susunannya, Penerbit Erlangga, Bandung.

Badan Pusat Statistik Makassar, 2010, Makassar Dalam Angka.

Clovis Heisath,1995,Arsitektur dari Segi Perilaku, AIA, Intermatra. 
Nature

National Academic Journal of Architecture 